\title{
Deep Eddies in the Gulf of Mexico Observed with Floats 0
}

\author{
HEATHER Furey AND AMY BOWER \\ Department of Physical Oceanography, Woods Hole Oceanographic Institution, Woods Hole, Massachusetts \\ PAUla PEREZ-Brunius \\ Department of Physical Oceanography, Ensenada Center for Scientific Research \\ and Higher Education (CISESE), Ensenada, Mexico \\ PETER HAMilton \\ North Carolina State University, Raleigh, North Carolina \\ ROBERT LEBEN \\ Colorado Center for Astrodynamics Research, University of Colorado Boulder, Boulder, Colorado
}

(Manuscript received 20 November 2017, in final form 9 August 2018)

\begin{abstract}
A new set of deep float trajectory data collected in the Gulf of Mexico from 2011 to 2015 at 1500- and 2500-m depths is analyzed to describe mesoscale processes, with particular attention paid to the western Gulf. Wavelet analysis is used to identify coherent eddies in the float trajectories, leading to a census of the basinwide coherent eddy population and statistics of the eddies' kinematic properties. The eddy census reveals a new formation region for anticyclones off the Campeche Escarpment, located northwest of the Yucatan Peninsula. These eddies appear to form locally, with no apparent direct connection to the upper layer. Once formed, the eddies drift westward along the northern edge of the Sigsbee Abyssal Gyre, located in the southwestern Gulf of Mexico over the abyssal plain. The formation mechanism and upstream sources for the Campeche Escarpment eddies are explored: the observational data suggest that eddy formation may be linked to the collision of a Loop Current eddy with the western boundary of the Gulf. Specifically, the disintegration of a deep dipole traveling under the Loop Current eddy Kraken, caused by the interaction with the northwestern continental slope, may lead to the acceleration of the abyssal gyre and the boundary current in the Bay of Campeche region.
\end{abstract}

\section{Introduction}

The Gulf of Mexico (GOM) is often characterized as a two-layer circulation system, forced by the Loop Current (LC; an upstream branch of the Gulf Stream), that enters the GOM through the 2000-m-deep Yucatan Channel to the south, travels anticyclonically through the eastern Gulf, and exits through the 800-m-deep Florida Straits to the east. The LC extends into the

\footnotetext{
Supplemental information related to this paper is available at the Journals Online website: https://doi.org/10.1175/JPO-D-170245.s1.
}

Corresponding author: Heather Furey, hfurey@whoi.edu
GOM to varying degrees with a northwestward extent of up to $28^{\circ} \mathrm{N}, 90^{\circ} \mathrm{W}$ (Fig. 1a; Leben 2005; Schmitz 2005; Oey et al. 2005). This current extends vertically to about 800-m depth (Candela et al. 2002) at the entrance and exit of the Gulf.

The LC periodically pinches off a large (200-400-km diameter) warm anticyclonic eddy, or LC eddy (LCE). The shedding of an LCE occurs irregularly about every 4-18 months (Sturges and Leben 2000), and the LCE, once detached, drifts westward or southwestward until its demise at the western boundary (e.g., Vukovich 2007). The triggers for LCE shedding are the subject of ongoing research, attributed to several mechanisms including baroclinic instabilities of the LC, transport variability at the Yucatan Channel and Florida Straits, and 

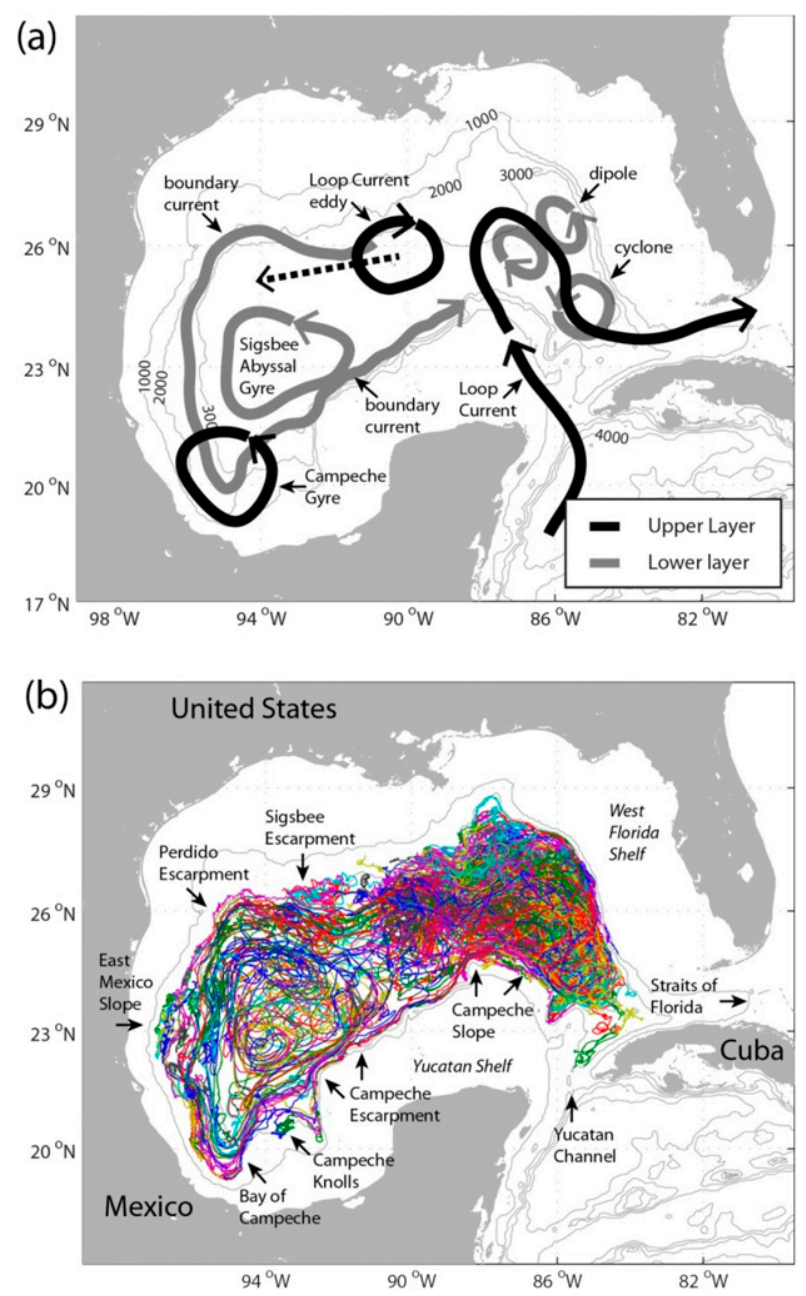

FIG. 1. (a) Schematic of quasi-permanent circulation features of the upper $(\sim 0-1000 \mathrm{~m})$ and lower (from $\sim 1000 \mathrm{~m}$ to the seafloor) layers of the Gulf of Mexico. Locations for the deep circulation features were taken from 2011-15 gridded mean velocity fields derived from RAFOS float data at 1500- and 2500-m depth (PPB), and the location of the surface Campeche Gyre location was taken from gridded surface drifter data during 2007-12 (Perez-Brunius et al. 2013). The Loop Current and Loop Current eddy are shown for a time when the eddy has just pinched off the Loop Current and is traveling westward. The dashed black line indicates the approximate direction of travel. Bathymetry is drawn at 1000-, 2000-, and 3000-m depth. (b) RAFOS trajectories collected from 2011 to 2015 that are used in this study. Each color indicated a separate trajectory. Geographic features relevant to this study are marked. Bathymetry rendered as in (a).

interaction of the Loop Current with cyclonic eddies formed both by local and remote processes (e.g., Donohue et al. 2016; Athié et al. 2012; Oey et al. 2005; Fratantoni et al. 1998; Zavala-Hidalgo et al. 2003; Jouanno et al. 2016; Sturges et al. 2010; Sheinbaum et al. 2016). The LCEs travel westward until they ultimately dissipate upon reaching the western boundary, contributing to the exchange of momentum, salt, and heat between the Caribbean and the interior of the Gulf of Mexico (e.g., Vidal et al. 1992).

The dynamics of the GOM can be largely explained by an upper layer $(<1000 \mathrm{~m})$ dominated by the surfaceintensified LC and mesoscale eddies and the bottom layer $(>1200 \mathrm{~m})$ with nearly depth-independent currents and density fields and near-bottom-intensified flows along the boundaries due to the presence of topographic Rossby waves (TRWs) (e.g., Sheinbaum et al. 2007; Hamilton 2009; Hamilton et al. 2016a, 2018; Donohue et al. 2007, 2008, 2016; Tenreiro et al. 2018). Until recently, the basinwide deep-layer circulation has been mostly unexplored owing to a lack of observations, although more recent observational programs have studied the upper-lower-layer dynamical coupling, resulting in deep vortices in the abyssal plain, as well as the propagation of TRWs along the boundaries (e.g., Hamilton 1990; Hamilton et al. 2016a; Donohue et al. 2016; Kolodziejczyk et al. 2011; Tenreiro et al. 2018).

"A Lagrangian Approach to Study the Gulf of Mexico's Deep Circulation" project funded by the Bureau of Ocean Energy Management (BOEM; Hamilton et al. 2016b) yielded an unprecedented dataset of lowerlayer RAFOS float trajectories at the 1500- and 2500-m levels (Fig. 1b). The data covered the years approximately 2011-15. From these data, Pérez-Brunius et al. (2018, hereafter PPB) were able to calculate the first basinwide mean pseudo-Eulerian deep circulation field (Fig. 1a), as well as other mean kinematic properties. In the mean, there exists a cyclonic boundary current around most of the deep perimeter of the GOM, varying in location between the 2000- and 3000-m isobaths, with the exception of the far-eastern Gulf. Large sections of this deep perimeter are bounded by steep escarpments (e.g., the Sigsbee, Perdido, Campeche, and the West Florida Escarpments; Fig. 1b). The PPB study also found a persistent cyclonic gyre in the lower layer of the western Gulf, named the Sigsbee Abyssal Gyre [SAG; distinct from the upper-layer cyclonic Campeche Gyre (CG) farther south; Pérez-Brunius et al. 2013], centered over the deepest part of the basin. And, as previously documented (Hamilton et al. 2014; Donohue et al. 2016), there was a deep cyclone and cyclone-anticyclone dipole under the LC in the eastern Gulf. In the LC region, Donohue et al. (2016) showed that these lowerlayer eddies are dynamically driven and linked to upperlayer circulation features. It is not certain if these deep eddies are in the float-derived mean fields because they are always present, or if they are episodic and depend on the position and extent of the LC and are imprinted on this mean field as a result of the sampling window of the float observations. 
In the western Gulf, several types of deep variability have been seen in numerical models, including a deep dipolar vortex structure, coupled with an upper-layer, westward-traveling LCE (e.g., Hurlburt and Thompson 1982; Welsh and Inoue 2000; Romanou et al. 2004; Sturges et al. 1993; Sutyrin et al. 2003). Deep dipoles (DDs) over a flat bottom may result from potential vorticity conservation in the lower layer $(f+\zeta / H=$ constant, where $f$ is planetary vorticity, $\zeta$ is the vertical component of relative vorticity, and $H$ is the lowerlayer thickness). Over the abyssal plain of the Gulf of Mexico, dipoles form as a response to the contraction and expansion of the lower layer associated with a translating LCE (Fig. 2). As an LCE moves westward, the squeezing of the lower layer in front of the center of the upper-layer anticyclone (LCE) generates negative relative vorticity, and an anticyclone is spun up (Cushman-Roisin et al. 1990; Welsh and Inoue 2000). By the same process, the lower layer behind the LCE is stretched and a cyclone is spun up. The deep anticyclone leads, the cyclone follows, and the major axis of the dipole is directed along the translation path of the LCE.

Tenreiro et al. (2018) have found evidence of these deep dipolar structures under LCEs in a mooring array spanning the far-western GOM from the 3500-m isobath $\left(\sim 95^{\circ} \mathrm{W}\right)$ to the western boundary, from 2008 to 2013, for nine separate LCE events. The mooring resolution was too coarse to resolve the deep eddy length scales, but peak speeds of the leading edge of the deep anticyclone were measured 10-20 days before the peak speeds of the leading edge of the upper-layer LCE (Tenreiro et al. 2018). Azimuthal speeds of the deep dipole (or modon) were observed to be up to $15 \mathrm{~cm} \mathrm{~s}^{-1}$. Model results (Welsh and Inoue 2000; Romanou et al. 2004) show that the deep dipole eddies' lengths scales are approximately $50-100 \mathrm{~km}$ smaller than the upperlayer LCE. Specifically, the range of diameters for the upper-layer LCE were $350-400 \mathrm{~km}$, whereas the diameters of the deep cyclone dipole component were 250-300 km (Welsh and Inoue 2000).

Another source of deep variability, TRWs, have been observed along the north and northwest continental slopes of the Gulf with wavelengths of $150-250 \mathrm{~km}$ and spectral peaks observed at periods of 25 and 40-100 days (Hamilton 1990, 2009) and along the western slope of the Bay of Campeche with wavelengths of $90-140 \mathrm{~km}$ and periods of 5-60 days (Kolodziejczyk et al. 2011). In modeling studies, Oey and Lee (2002) found that lowerfrequency TRWs are found dominantly across the northern and northwestern Gulf; a coarse model grid did not allow them to explore higher-frequency wave phenomena. Sutyrin et al.'s (2003) process-oriented model

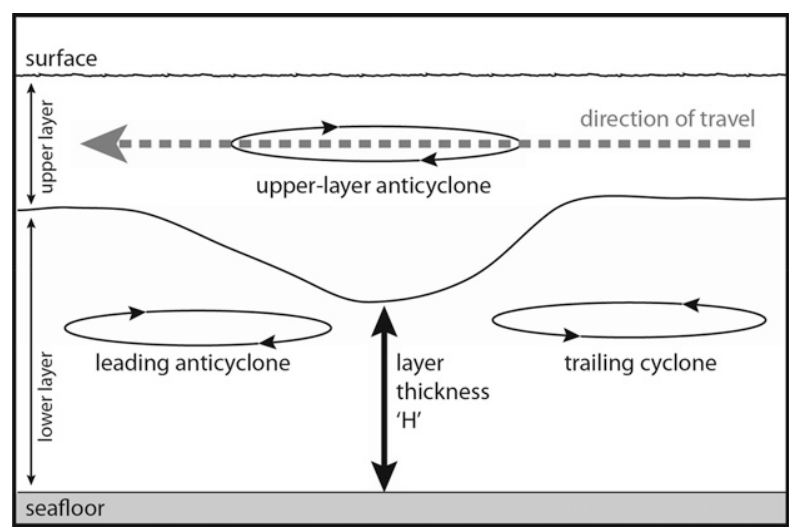

FIG. 2. Lower layer spinup of dipole (modon) in response to drifting upper-layer anticyclone.

study shows the combined effect of deep dipole circulation and TRWs in the western Gulf, concluding that as the deep dipole eddies impinge on the western boundary, energy is transformed to TRWs. The observations by Tenreiro et al. (2018) and numerical studies (e.g., Welsh and Inoue 2000; Romanou et al. 2004) show that the cyclone portion of the deep dipole persists longer than the anticyclonic member of the dipole, and as the LCE and leading anticyclone collide with the boundary and dissipate, the cyclone remains in the abyssal plain enhancing deep cyclonic circulation.

In this study, using the same float trajectory dataset as PPB, we identify coherent eddies in the float trajectories using wavelet analysis, resulting in the first census of the basinwide deep eddy population, including statistics of the eddies' kinematic properties. We identify a subset of eddies that appear to be distinct from the LCEassociated dipoles and TRW motions described above. These eddies, which we call Campeche Escarpment Eddies (CEEs), are formed in the northwestern tip of the Yucatan Peninsula and may be important for lowerlayer stirring and transport of properties between the Campeche Escarpment and interior Gulf. Finally, we discuss the possible dynamical mechanisms that may trigger the formation of these eddies.

In section 2, we describe data and methods used in this study. In section 3, we begin with the Gulf-wide eddy census and a detailed description of formation and kinematics of the CEEs. We then describe the conditions that affect the boundary and abyssal gyre circulation upstream of the escarpment that appear to be connected to CEE formation. Finally, we present evidence of a deep dipole under an LCE, which may initiate deep gyre and boundary current variability that could lead to CEE formation. A summary and discussion of the eddy census, CEE formation mechanisms, and the deep layer circulation evolution follows in section 4. 


\section{Data and methods}

\section{a. Float experiment design}

The BOEM-funded "A Lagrangian Approach to Study the Gulf of Mexico's Deep Circulation" has generated the most comprehensive set of observations of circulation in the deep $(>1000 \mathrm{~m})$ GOM to date (Hamilton et al. 2016b). Between July 2011 and June 2015, 158 neutrally buoyant, acoustically tracked floats, released in multiple settings in the eastern, central, and western Gulf, collected simultaneous position, temperature, and pressure data every eight hours at depths of 1500 (127 floats) and $2500 \mathrm{~m}$ (31 floats). In total, 194 float years of data were collected by 152 RAFOS (Rossby et al. 1986) and 6 RAFOS-equipped profiling APEX floats (Davis et al. 2001). The sampling rate of the floats was specifically chosen to allow accurate identification of the looping motion associated with coherent eddies, so four position data points per inertial period $(\sim 32 \mathrm{~h}$ at $24^{\circ} \mathrm{N}$ ). The float population in the Gulf was approximately 40 floats or more during the time period from July 2012 through June 2014 (PPB; Hamilton et al. 2016b), and it is during this time period that we had the best spatial coverage in the western Gulf. More information on the technical aspects of this project may be found in Hamilton et al. (2016b).

\section{b. RAFOS float tracking}

The raw RAFOS float data were converted from acoustic time signals to position ("tracked") using the software package ARTOA (Wooding et al. 2005). This software allows the manual extraction of times-ofarrival data and calculates 8-hourly positions based on a least squares algorithm involving distance between the float and the sounds source and speed of sound in water to yield position. The accuracy of float position is about $1-3 \mathrm{~km}$ owing to variations in sound speed and float and sound source clock accuracies, but the relative accuracy of adjacent positions is better, since all three factors affect each point similarly.

\section{c. Wavelet analysis}

The RAFOS and RAFOS-equipped APEX floats were at times embedded in flow that exhibited looping motion, indicative of coherent eddies capable of trapping and transporting water (and floats). To quantify eddy kinematics and generate a census of eddies in the deep GOM, we utilized MATLAB-based wavelet analysis software provided by J. Lilly (2015, personal communication). This methodology has been documented in a series of papers (Lilly and Olhede 2009a,b, 2010a,b, 2012), which were based on a prototype study by Lilly and Gascard (2006). The analysis method is performed by finding the "best fit" of the float trajectory data to a mathematical model for the displacement signal of a particle orbiting the center of an eddy, using a procedure known as wavelet ridge analysis. By using this analytical method, we were able to objectively quantify the number of cyclonic and anticyclonic coherent eddies in the dataset, along with statistics on their kinematic properties such as rotation period, diameter, azimuthal velocity, and Rossby number.

The wavelet detection software allows the user to modify input parameters of maximum and minimum ratios of rotation frequency to Coriolis frequency, wavelet duration, and ridge length cutoff for a minimum number of complete loops. The eddy rotation period was required to be at least twice the inertial period. The minimum number of complete trajectory loops was set to 3 , so that only eddies with at least three complete rotations were identified.

Algorithm output parameters include the segment of track identified as positively being in rotation, the residual trajectory once rotation is removed (i.e., trajectory of eddy center), and a variety of ellipse parameters, of which we report geometric mean radius $R$, azimuthal velocity $V$, and Rossby number (Ro, where Ro $=V / 2 R f$ or $\omega / f)$, the ratio of relative to planetary vorticity. Because of edge effects, we discarded output equal to one rotation period of the eddy at both the start and end of the eddy segment, as described in Bower et al. (2013) in their appendix titled "Extracting eddy signals from float trajectories." In practice, if a float was in an eddy for three complete loops, the values of radius, velocity, and Ro are based only on the mean value of the middle loop. Note that while the statistical parameters are affected by edge effects, the trajectory segment identified as being in an eddy, the eddy residual path, and the duration are not.

In certain cases, visual inspection of the resultant eddy track segments showed that some were part of the same eddy, but tracking discontinuities forced the wavelet analysis to identify the eddies as separate. We verified that separate eddies were really the same feature if the radius, velocity, and the Ro values were similar, and the float looked to have been in the same eddy based on visual character, location, and time. In other cases, we grouped floats into a single eddy when those floats appeared to have been trapped in the same eddy at the same time, again using the kinematic properties to help guide this decision. In the case where eddies were sampled by multiple floats, the statistics retained were the maximum radius, velocity, and lifetime among all the floats in the group and the mean pressure, temperature, and Ro value of all floats in the group.

Table 1 describes the mean statistics for all eddies. Note that since the radius is that of the float's trajectory, 
TABLE 1. Mean and standard deviation of eddy statistics by category, where $V$ and Ro are given as absolute values.

\begin{tabular}{lcccccc}
\hline \hline Eddy category & All & Anticyclones & Cyclones & Interior & Boundary & Campeche Escarpment \\
\hline Sample size & 49 & 26 & 23 & 30 & 17 & 2 \\
Radius (km) & $13 \pm 14$ & $8 \pm 7$ & $18 \pm 18$ & $18 \pm 16$ & $3 \pm 2$ & $17 \pm 11$ \\
$|V|\left(\mathrm{cm} \mathrm{s}^{-1}\right)$ & $9 \pm 8$ & $8 \pm 6$ & $11 \pm 9$ & $12 \pm 8$ & $3 \pm 2$ & $11 \pm 0$ \\
Period (days) & $10 \pm 6.0$ & $8 \pm 5$ & $12 \pm 7$ & $11 \pm 7$ & $8 \pm 6$ & $11 \pm 7$ \\
$\mid$ Ro $\mid$ & $0.18 \pm 0.10$ & $0.22 \pm 0.10$ & $0.14 \pm 0.09$ & $0.15 \pm 0.09$ & $0.23 \pm 0.11$ & $0.15 \pm 0.09$ \\
Duration (days) & $50 \pm 35$ & $48 \pm 36$ & $53 \pm 34$ & $55 \pm 30$ & $34 \pm 26$ & At least 140 \\
\hline
\end{tabular}

it represents a lower bound on the true eddy radius. The absolute value of $V$ and Ro were used to calculate the mean values, as some categories of eddies contained values of both sign. In a couple of cases, a float ended its preprogrammed mission while still embedded in an eddy: the duration was either not used to calculate the mean or noted, as in the case of the Campeche Escarpment eddies.

\section{d. SSH data and Loop Current eddy identification}

Sea surface height (SSH) is used to explore the relationship of the upper-layer circulation concurrent with the deep-layer RAFOS float trajectories. The SSH product used in this research was the gridded $\mathrm{SSH}$ data product $\left(0.25^{\circ} \times 0.25^{\circ}\right)$ produced at the Colorado Center for Astrodynamics Research (CCAR). The CCAR SSH product employs an estimate of the mean dynamic topography from a data-assimilative model (Leben et al. 2002) and is designed to accurately map mesoscale features in the Gulf. The gridded CCAR SSH product was tested against pressure sensing inverted echo sounder (PIES) SSH data during the eastern Gulf Loop Current Exploratory Program and was found to have an overall correlation of $\sim 0.94$, with generally lower correlation near the Florida Escarpment and higher correlation in deeper water. The regression of the PIES SSH with both the CCAR AVISO SSH and along-track SSH was also nearly 1 , with the CCAR SSH underrepresenting the PIES SSH signal by about $0.2 \mathrm{~cm} \mathrm{~cm}^{-1}$. In practice, the CCAR SSH value of $17 \mathrm{~cm}$ would measure about $3 \mathrm{~cm}$ less than the PIES SSH signal (see Figs. 2.7-6, 2.7-7, and 2.7-9 in Hamilton et al. 2014). A more detailed description of the satellite combination and objective mapping process may be found in Hamilton et al. (2014, 2016b).

The identification of the LCEs by the $17-\mathrm{cm}$ sea surface height contour has been documented in previous studies (e.g., Leben 2005), and we use the same convention here. We also use along-track sea surface height anomalies from the integrated along-track altimetry dataset (available online at http://podaac.jpl.nasa.gov/dataset/MERGED_ TP_J1_OSTM_OST_CYCLES_V3). This dataset is produced by NASA's Ocean Surface Topography Science
Team (OSTST) and contains data from the TOPEX/ Poseidon, Jason-1, and Ocean Surface Topography Mission (OSTM)/Jason-2 satellites. The along-track data have a $\sim 5$-km along-track resolution.

\section{Results}

\section{a. Gulf-wide eddy census}

Out of a total of 158 floats, 44 were trapped in coherent eddies of three rotations or more, and some floats were trapped in multiple eddies during their missions (Fig. 3). Out of 60 separate eddies identified with the wavelet analysis, we found that 49 were unique. In total, 2716 float days were measured in eddies of at least three loops, or $4 \%$ of the total trajectory data. (With a relaxed criterion of two loops, $7 \%$ of the floats measured coherent eddy behavior.) This result does not mean that the remaining $96 \%$ (or $93 \%$ ) of the data showed stable flow patterns; rather, that the float eddying behavior did not exhibit coherent looping.

The results of the wavelet analysis show that a nearly equal number of cyclones (23) and anticyclones (26) were present in this dataset (Table 1), and approximately 4 times more eddies were found at $1500 \mathrm{~m}$ compared to $2500 \mathrm{~m}$, reflecting the $4: 1$ ratio between the number of shallow and deep floats deployed. A qualitative examination of the eddy trajectory dataset (Fig. 3) indicates that more eddies were found in the eastern than the western Gulf. This is true quantitatively as well: per unit trajectory, and using $90^{\circ} \mathrm{W}$ as the demarcation between east and west, a float was more likely to be caught in an eddy in the east $(5 \%$ of the time for a $3+$ loop eddy and $10 \%$ of the time for a $2+$ loop eddy) than the west ( $2 \%$ of the time for $3+$ loops, $5 \%$ of the time for $2+$ loops).

Eddies fall into three categories based on region of formation. We will consider both float depths together as velocity is relatively uniform with depth in the deep layer (Hamilton 1990; Tenreiro et al. 2018), and there were no outstanding differences in eddy distribution between the two depths. The first type consists of "interior" eddies located in water depth greater than $2500 \mathrm{~m}$ (but excluding the anticyclones in deep water 


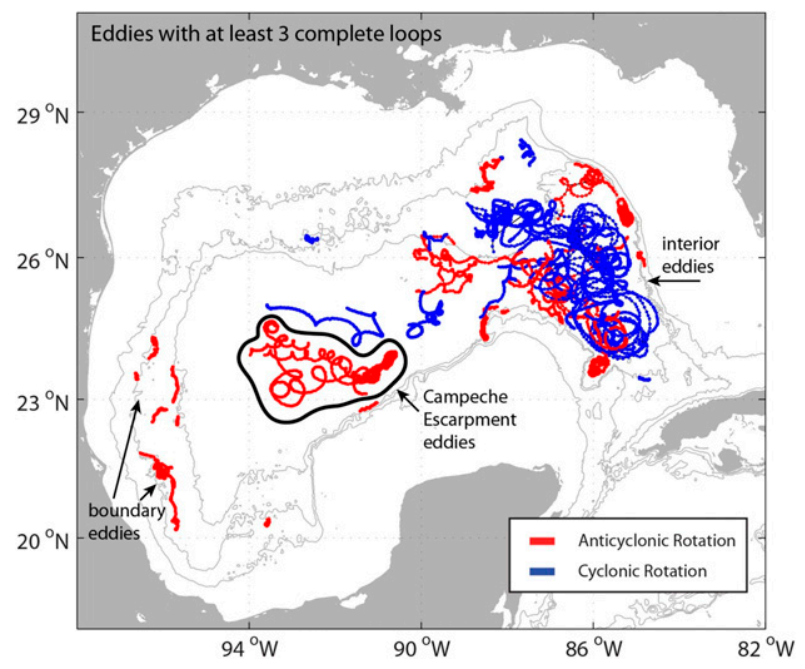

FIG. 3. Eddies with three or more complete loops that were identified in the trajectory data shown in Fig. 1b. Only the segments of trajectories that were identified as being in a coherent eddy are rendered, red for anticyclonic and blue for cyclonic rotation. The three categories of eddies discussed in the text, boundary eddies, interior eddies, and CEEs, are labeled. Each 8-hourly position is marked by a dot. Bathymetry rendered as in Fig. 1.

west of about $90^{\circ} \mathrm{W}$ outlined in Fig. 3 and discussed further below), which were predominantly (20 out of 30) cyclonic. The second category comprises "boundary" eddies that were present around the perimeter of the Gulf, located between the mean cyclonic boundary current and the shelf, inshore of the 2500-m isobath. These eddies were usually anticyclones (14 out of 17 eddies) and were found particularly along the western boundary and the Campeche Escarpment. Last, there were two anticyclones that appear to be generated offshore of the northwest Yucatan Peninsula, which we call CEEs.

An example of a coherent eddy observed by the floats is illustrated with float 1223, launched on 22 August 2013 at $1500 \mathrm{~m}$ and surfacing 630 days later on 14 May 2015 (Fig. 4). It became entrained in a cyclonic eddy typical for the eastern basin, and we group it in the interior eddy category. As the LC front shifted westward, the cyclone translated from northeast to southwest underneath (Fig. 4, middle panels). This type of deep eddy path has been observed under the LC by a mooring-PIES array (Donohue et al. 2016). The looping radius varied between 45 and $55 \mathrm{~km}$, azimuthal velocity between 25 and $30 \mathrm{~cm} \mathrm{~s}^{-1}$, and the rotation period was about 13-14 days. This scale of deep eddy in the eastern Gulf has also been found in modeling studies (see Fig. 3 in Oey et al. 2005), though the eddy measured by the RAFOS float had higher azimuthal speed than the model eddies $(\sim 30$ vs $\sim 10 \mathrm{~cm} \mathrm{~s}^{-1}$ ). Ro was about 0.08 , indicating that it was essentially in geostrophic balance, that is, a linear eddy. This eddy persisted for 51 days.

Across all eddies, the mean looping period was 10 days, $|V|$ was $9 \mathrm{~cm} \mathrm{~s}^{-1}, R$ was $13 \mathrm{~km}$, and $|\mathrm{Ro}|$ was 0.18 (Table 1). The interior eddies and CEEs were larger (mean $R$ of $17-18 \mathrm{~km}$ ) than the boundary eddies (mean $R$ of $3 \mathrm{~km}$ ). Mean $|V|$ and mean rotational period were similar for interior and CEEs as well, $11-12 \mathrm{~cm} \mathrm{~s}^{-1}$ and 11 days, respectively, compared to the slower $\left(3 \mathrm{~cm} \mathrm{~s}^{-1}\right)$ and shorter period ( 8 days) boundary eddies. Despite the slower spin rate of the boundary eddies, their mean $|\mathrm{Ro}|$ was higher (0.23) than the CEEs or interior eddies (0.15), reflecting the larger ratio of azimuthal speed to looping radius. CEEs are the longest lived by a factor of at least 3 , continuously observed for an average of 4.7 months. (These eddies were likely to have persisted for longer; the floats surfaced while still embedded in the CEEs.)

At $1500 \mathrm{~m}$, cyclonic eddies were warmer than the anticyclones, with a mean temperature of $4.35^{\circ} \pm 0.08^{\circ} \mathrm{C}$ (at a mean pressure $1569 \mathrm{~m}$ ) versus $4.29^{\circ} \pm 0.03^{\circ} \mathrm{C}$ (mean pressure $1545 \mathrm{~m}$ ). The difference, though not statistically significant, may reflect the different origins of most of the cyclonic and anticyclonic eddies: most of the cyclones observed by these floats were found in the eastern Gulf (Fig. 3), where, using all isopycnally gridded historically available profile data (Curry and Nobre 2013), at 1600-m depth, water temperatures are warmer by up to $0.1^{\circ} \mathrm{C}$ in the eastern compared to the western GOM. This is likely due to the influence of the relatively warm LC. For example, an eastern Gulf cyclone is partially under a LC meander crest and thus in warmer water (Donohue et al. 2016). We found no significant differences in temperature or pressure between different eddy categories.

\section{b. CEEs}

Eddies observed off the Campeche Escarpment are remarkable in that they were long-lived and appear to be formed in a specific geographic location: at the northeasternmost extent of the SAG, downstream of where it separates from the Campeche Escarpment. There were many examples of floats exhibiting looping behavior in this region, especially along the northern boundary of the SAG (see Fig. 7 in PPB). Most of this looping behavior was not identified as coherent using the wavelet technique, as many of these floats were not trapped in the eddies for an extended time. The gulfwide eddy kinetic energy (EKE) distribution shows a localized "hot spot" at this location, with only the region under the LC showing higher EKE (PPB). We classify CEEs as anticyclonic eddies that were identified with the wavelet analysis and formed at this location.

Floats depicting the formation of two CEEs are shown in Fig. 5. The floats were launched along the 2000-m 

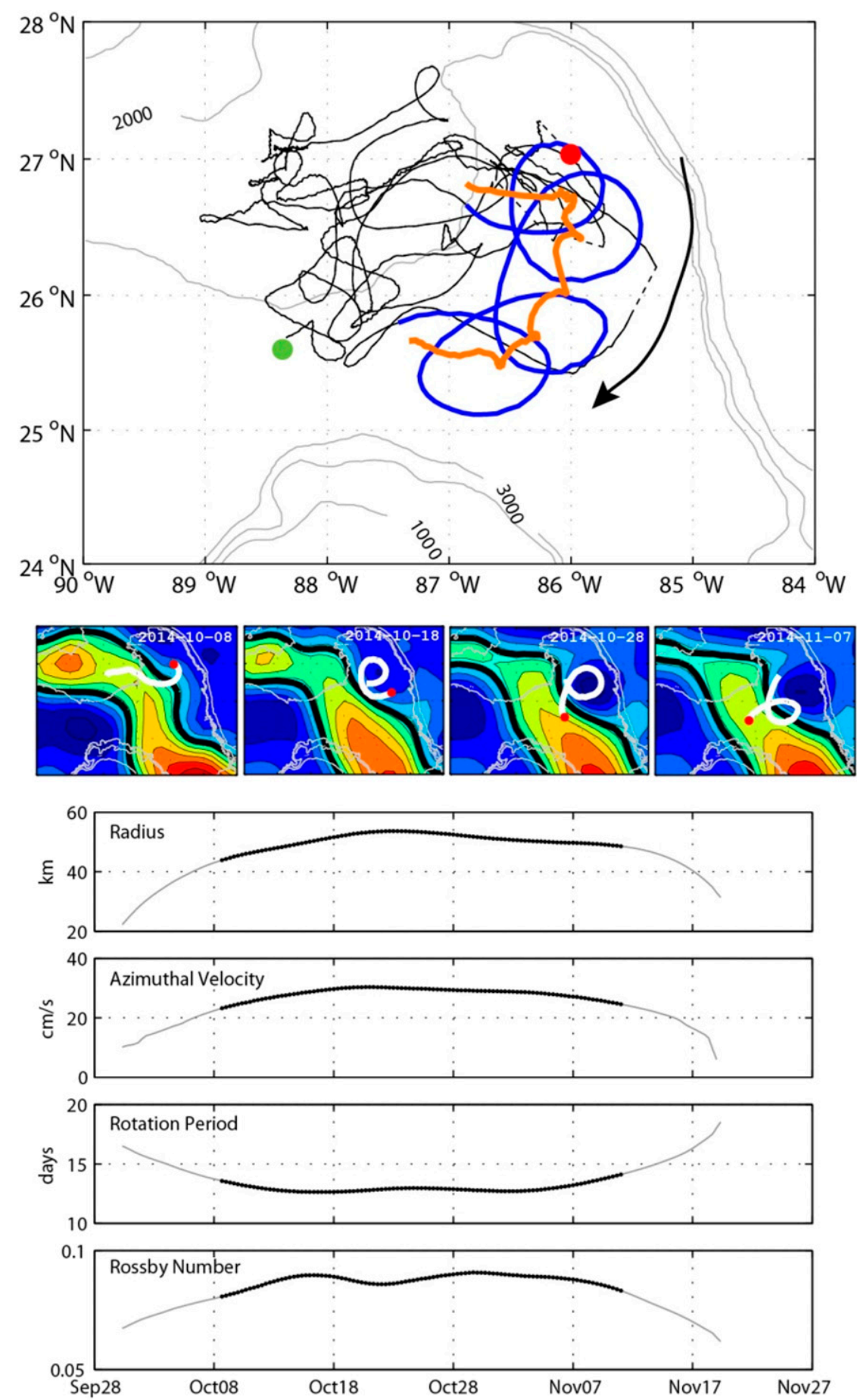

FIG. 4. Example of an interior eddy. (top) Float trajectory with the coherent eddy segment of the trajectory highlighted in blue, and the residual trajectory rendered in orange. Float launch location (green dot) and surface location (red dot) are shown. Bathymetry rendered as in Fig. 1. (middle) Four panels showing 10-day evolution of the SSH field and float trajectory, with 0 -cm contour drawn as a thick black line, 20-day float trajectory segments drawn in white, and a red dot marking the head of the trajectory segment. (bottom) Four plots showing the evolution of eddy parameters derived from the wavelet analysis during the lifetime of the eddy (blue track segment in the top panel). The gray tail segments on either end of each parameter are the portion affected by edge effects (see text); the black segments are valid values for the eddy. 
isobath in the western Bay of Campeche on 13 (float A) and 15 (float B) September 2012. Both floats drifted at $\sim 1500$-m depth for their full 630-day mission. They first drifted slowly $\left(\sim 5 \mathrm{~cm} \mathrm{~s}^{-1}\right)$ around the perimeter of the Bay of Campeche and when they reached the western corner of the Campeche Escarpment were entrained in a fast-moving current along the steep slope. The floats showed that the current detached from the slope and formed anticyclonic eddies, which then drifted westward. The two CEEs measured by floats A and B had mean radii of 24 and $9 \mathrm{~km}$, respectively, and periods of 16 and 6 days, and both had mean azimuthal velocities of $-11 \mathrm{~cm} \mathrm{~s}^{-1}$. The eddies lived for at least 129 (A) and 152 (B) days. The linear relationship of $V$ versus $R$ over eddy B's lifespan (Fig. 5, inset) indicates that this CEE was in solid body rotation out to a radius of at least $12 \mathrm{~km}$.

The formation of these two eddies is shown in a time series of trajectory segments (Fig. 6). Both floats accelerated from about $5 \mathrm{~cm} \mathrm{~s}^{-1}$ in the Bay of Campeche region to $30 \mathrm{~cm} \mathrm{~s}^{-1}$ upon reaching the Campeche Escarpment (Figs. 6a,b). Both floats (Fig. 6c) diverged from the escarpment wall at a bump in the bathymetry, crossed lines of constant planetary potential vorticity $(f / H)$, and began looping, float A on 31 December 2013 and float B on 3 January 2014. Float A began to make one large loop (with diameter $\sim 80 \mathrm{~km}$ and period $\sim 25$ days) about 3 days after leaving the escarpment. Float B passed the same location about 2.5 days later and began looping about 7 days after leaving the boundary, although evidence of cusping appeared in the float trajectory about 3 days after separation. Float $B$ formed smaller loops that were about $18 \mathrm{~km}$ in diameter. The larger anticyclonic eddy began drifting westward after the first loop, where the smaller eddy made three complete rotations in place before beginning to drift westward.

We examined the TOPEX/Poseidon, Jason-1, and OSTM/Jason-2 satellites along-track altimeter data for the period 1 January 2013 to 1 June 2014 to look for sea surface height anomalies that might correspond to the CEEs, indicating a possible direct relation to upperlayer flows. We do find small $(5-10 \mathrm{~cm})$ positive anomalies in SSH as the floats cross satellite track lines (Fig. 6d) near the eddy formation site. However, we find similar (and sometimes larger) magnitude positive anomalies when floats not embedded in CEEs cross the same track lines. With no strong evidence of a surface expression, we proceed assuming that CEE formation is governed primarily by lower-layer dynamics.

\section{c. Upstream conditions during CEE formation}

To learn more about eddies that form off the Campeche Escarpment, we look at all the floats that drifted through this region. The mean SAG and boundary

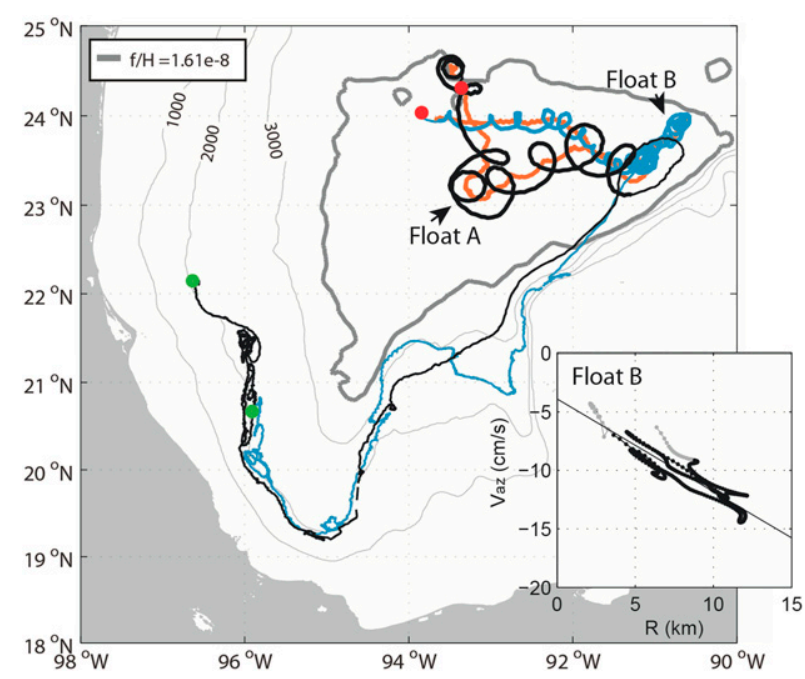

FIG. 5. Trajectories from two 1500-m floats that were in CEEs off the Campeche Escarpment. The bold blue and black lines indicate when the float was embedded in a coherent eddy, thin lines mark the remaining trajectory of each float, and the orange lines are the residual pathway of each eddy. One $f / H$ contour is marked, following PPB. Bathymetry rendered as in Fig. 1. Inset: The relationship of float azimuthal velocity $V$ and eddy radius $R$ for float B. Dots mark 8-hourly positions. The black portion of the trajectory shows when the values of $V$ and $R$ are mathematically and physically accurate.

current are closest in proximity to each other at the northwest corner of the Campeche Escarpment (PPB and Fig. 1). This corner is where the flow of the SAG and the boundary current converge, resulting in a narrow $(\sim 45 \mathrm{~km})$ and well-defined flow, which has the highest mean kinetic energy of the entire Gulf of Mexico (PPB). Approximately $100 \mathrm{~km}$ downstream of the corner, floats exit the slope toward the interior (Fig. 6a). We will refer to the cross section where this occurs as the "separation region," shown as a black line in Figs. 6 and 7.

A total of 25 floats passed through the separation region (Fig. 7), and we sort their trajectories into four groups: those that remain in the boundary current, those that stay in the SAG, those that separate then meander east out of the SAG, and, finally, those that separate from the boundary but end up in CEEs. An expanded view of this separation region (Fig. 7b) shows that the flow separates from the boundary where there is a bump in the slope topography, similar to the two CEE floats (also included here) shown previously (Figs. 6 and 7). We note here that upstream of this separation region, the two CEE floats were in the boundary current, as were other floats that end up in the SAG, indicating boundary current-gyre exchange.

The cross-slope position of the floats when they pass the separation region has some bearing on where the floats end up (Fig. 8a). The inshore-most floats, located above the escarpment, stayed in the boundary current from this point 

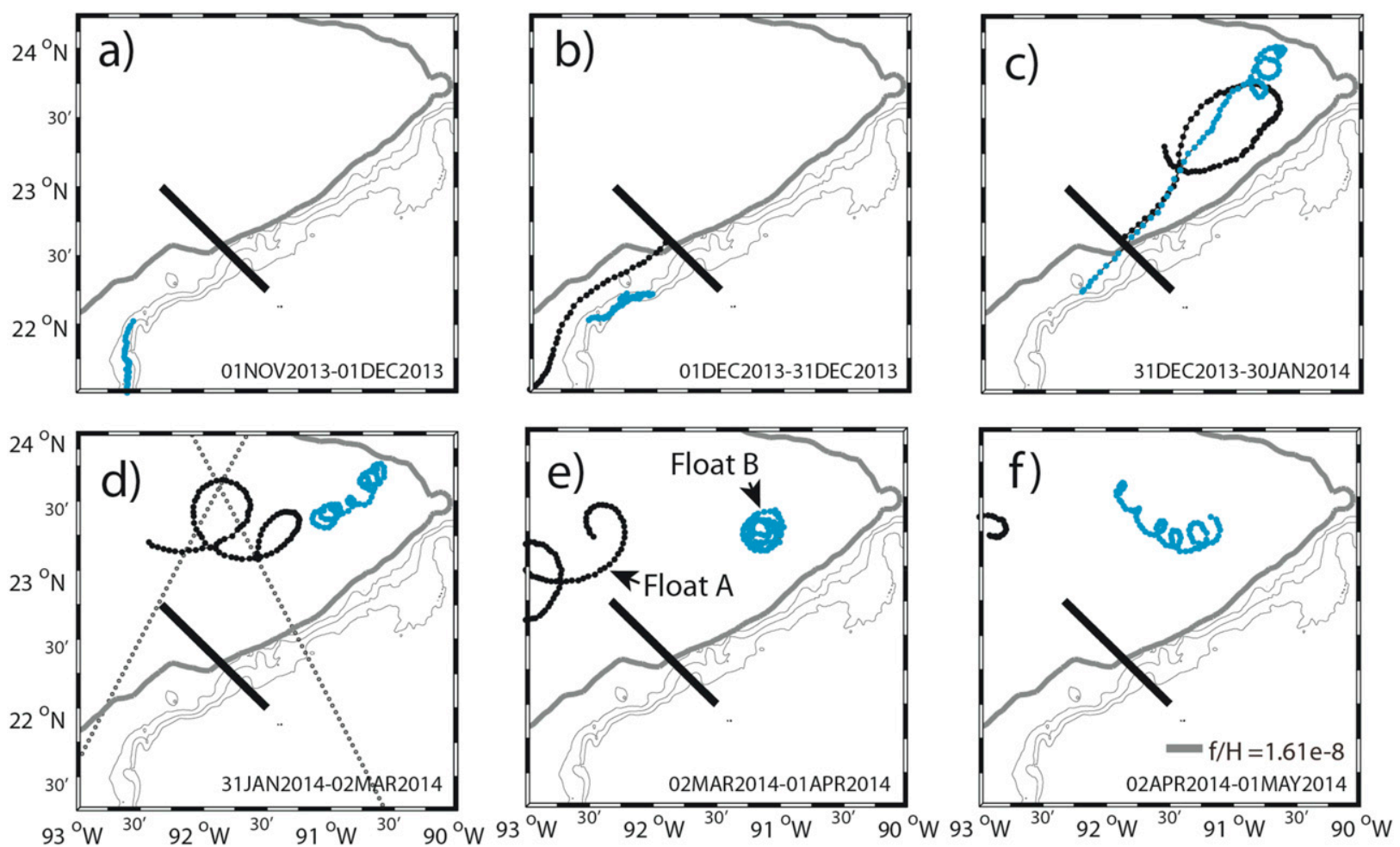

FIG. 6. (a)-(f) Eddy formation process shown in 30-day segments for the two floats shown in Fig. 5. Dots mark 8-hourly positions. The black line segment perpendicular to the bathymetry marks the cross-slope location of the separation region described in the text and in subsequent figures. Bathymetry and the $f / H$ contour depicted as in Fig. 5. Two altimetry tracks depicted as dotted lines in (d) were used to look at along-track altimetry variations during the times the CEEs passed by the tracks.

forward. The remaining floats diverge offshore of the slope, with those farthest from the slope tending to drift toward the eastern basin, while the rest turn westward into the flow of the SAG, although there are exceptions to this rule. The two floats that get entrained in CEEs are found in positions relatively close to the slope.

Based on some previous work (e.g., Bower et al. 1997), we hypothesize that CEE formation may be related to the speed in the SAG-boundary current at the separation region. The 22-month long time series of speed for each float as it crossed the separation region (Fig. 8b) shows that the float speeds in the SAGboundary current ranged from 4 to $32 \mathrm{~cm} \mathrm{~s}^{-1}$. The boundary current floats were the most sluggish (average speed of $6 \mathrm{~cm} \mathrm{~s}^{-1}$ ), while floats that left the slope had a wider range of speeds, with an average of $15 \mathrm{~cm} \mathrm{~s}^{-1}$. There was one month-long period in January 2014 where the highest velocities were recorded, which coincides with the time when two the CEE floats crossed this section with measured speeds of 28 and $32 \mathrm{~cm} \mathrm{~s}^{-1}$.

\section{d. Possible upstream forcing of CEEs}

The above description of a possible connection between flow speed and CEE formation raises the question of how such accelerations might be driven. Although the float dataset described in this paper is the most extensive to date, it is still not sufficient to definitively identify such a process. Here we simply put forward some evidence suggesting that LCE collision with the western boundary may be a catalyst. In previous work, it has been shown that such events can trigger fluctuations in the GOM's deep boundary current, due to either the impingement of a deep dipole under an LCE (Welsh and Inoue 2000; Romanou et al. 2004; Tenreiro et al. 2018), TRW generation (e.g., Hamilton 2009), or both (Sutyrin et al. 2003).

In August 2013, LCE Kraken pinched off from the LC and drifted westward until December 2013 (Hamilton et al. 2018) when it broke apart and dissipated on the western boundary. The behavior of the deep floats during this event is depicted in a multipanel time series, from 1 August 2013 through 15 January 2014, that is, from the time Kraken first entered the western Gulf to when the CEEs were formed (Fig. 9). Kraken can be seen entering the region from the west in late August 2013 (Fig. 9b), progressing westward across the abyssal plain between early September through December 2013 (Figs. 9c-j), and elongating along the northwestern Gulf slope in late December through mid-January (Figs. 9k,l). 

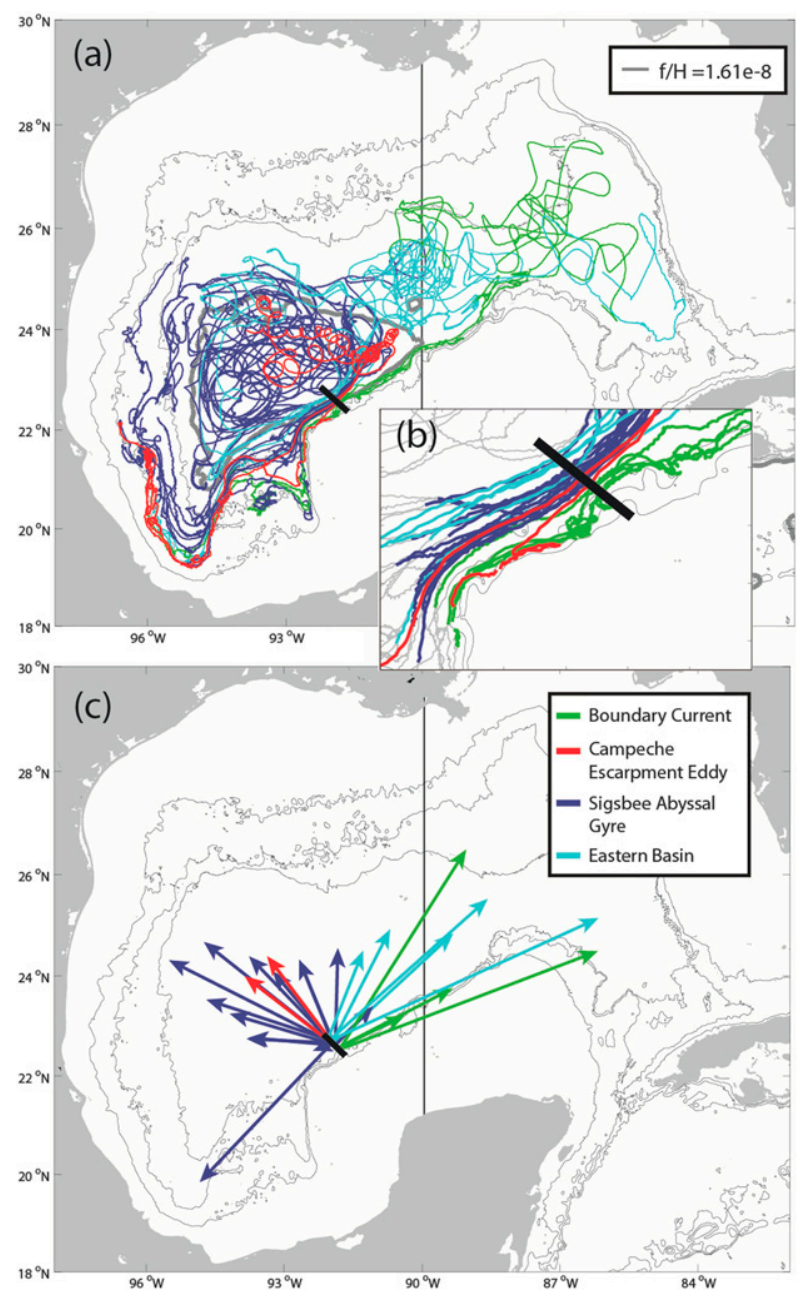

FIG. 7. (a) Full 630-day trajectories of all floats that were transported through the southwest SAG and boundary current located at the western corner of the Campeche Escarpment. (b) Enlargement of the separation region. (c) Displacements of each float from the northwest Campeche Escarpment corner to the last tracked position. The short black line segments in all panels mark the location of the section that will be used in Fig. 8 . The $90^{\circ} \mathrm{W}$ meridian has been highlighted for reference. Floats have been color coded by float outcome (see legend and text). Bathymetry and $f / H$ contour depicted as in Fig. 5.

The float trajectories, although patchy in distribution, captured some interesting basinwide changes in circulation through this period. Before Kraken entered the western Gulf, the float displacements were short, indicating relatively slow speeds, and there was no clearly organized flow pattern (Fig. 9a). When Kraken began to enter the region in mid-August (Fig. 9b), the floats were still slowly drifting, but the character of the deep flow began to change by the start of September (Fig. 9c), where longer (i.e., faster) trajectories were present along the Sigsbee Escarpment leading the LCE as it pressed into the western Gulf. Reversals in the direction of along-slope flow were also observed (Figs. 9c-f), especially along the Sigsbee Escarpment and over the western slope (to about $23^{\circ} \mathrm{N}$ ), as the LCE progressed westward.

Enough floats were present in mid-November to clearly delineate flow consistent with a dipole under Kraken between $92.5^{\circ}$ and $95^{\circ} \mathrm{W}$ (Figs. 9h), oriented from west-northwest to east-southeast, and generally aligned with Kraken's trajectory toward the west as it moved off the Sigsbee Escarpment and into deeper waters over the abyssal plain. (An expanded view of the floats during the November 2013 time period, including gridded float velocities, may be found in Fig. S1 of the online supplemental material.) As Kraken began to move toward the northwest, diminishing in area and elongating along the northwestern slope (Figs. 9i-1), evidence of the dipole is lost (Figs. 9i,j), possibly due to poor data coverage. There is evidence of anticyclonic circulation northwest of the SAG in Figs. 9k and 9l, which may or may not be a remnant of the dipolar flow measured by the floats in Fig. 9h. However, from November 2013 to mid-January 2014, floats display an intensified and well-defined cyclonic circulation over the abyssal plain (Figs. 9h-1) compared to weeks prior to Kraken's arrival (Figs. 9a-d).

As Kraken impinged on the northwestern slope, the float speeds and displacements in the southwestern GOM increased (Figs. 9j-1). The measured accelerations appeared to be particularly confined to floats drifting in the region above the 2500- to 3000-m isobaths. This acceleration appeared first in the Bay of Campeche (Fig. 9i) and then, in the next panel, on the eastern side of the Bay of Campeche and along the northwest corner of the Campeche Escarpment. By early January 2014 (Fig. 91), the highest along-boundary speeds were concentrated along the western end of the Campeche Escarpment, and the CEEs were formed. By late January (not shown) most of the floats slowed all across the region (similar in character to Fig. 9a), including the SAG, except for the floats entrained in the CEEs.

To quantify the time dependence of the float velocities, we isolated float trajectory segments into four regions, and plotted along-isobath velocity versus time (Fig. 10). Along-isobath velocity was computed by rotating float velocity into along- and across-isobath components, where the bathymetric gradient was estimated at each float position by fitting a plane to the digital bathymetric data (Hamilton et al. 2016b) in a $\sim 50 \mathrm{~km} \times 50 \mathrm{~km}$ box centered at the float position. The along-isobath velocity component was then smoothed with a second-order low-pass Butterworth filter (run forward and backward to eliminate phase shifting) with a 3-day cutoff period. We limited the data to the period from 1 June 2013 through 1 May 2014, which 


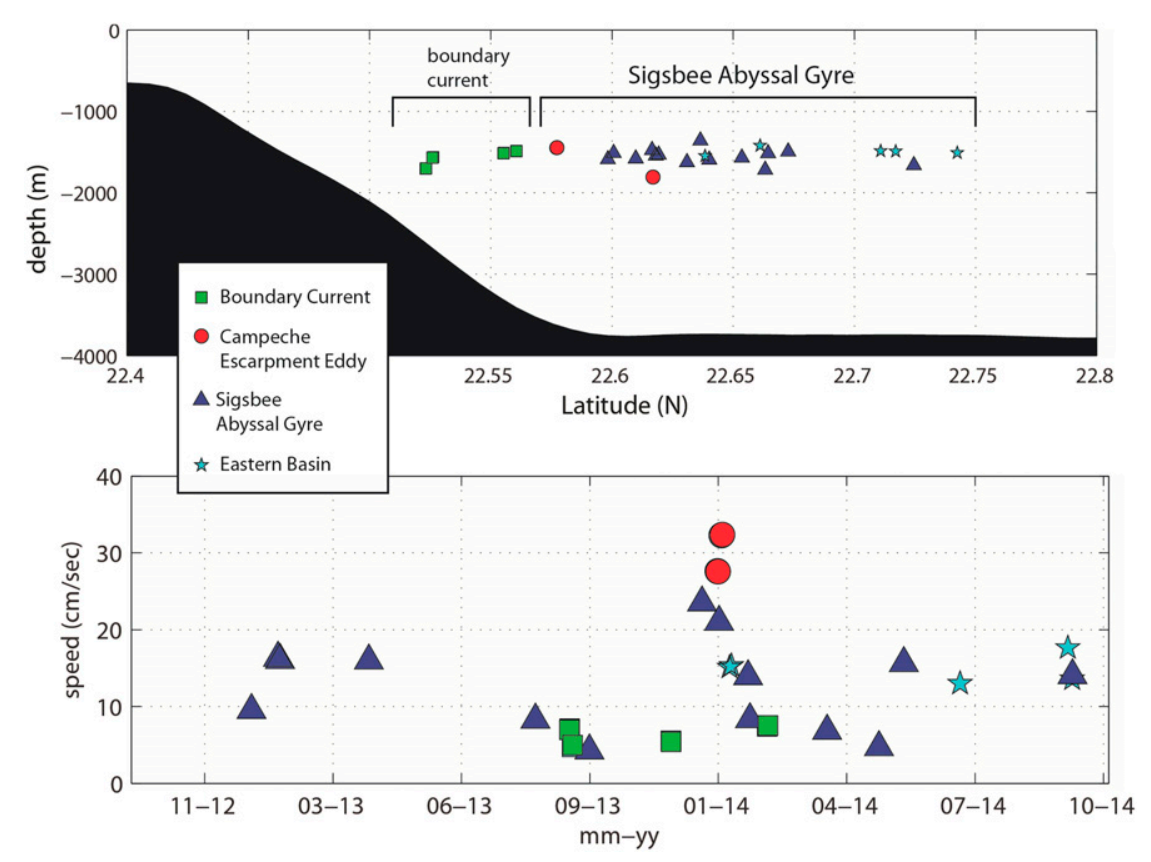

FIG. 8. (a) Cross-slope float positions and (b) float velocity vs time at the separation region marked in Figs. 6 and 7. In both panels, marker shape and color indicate downstream outcome.

includes the life of Kraken in the western Gulf. Figure 10a shows the four regions of float trajectories that show different time evolutions of velocity: in the northwest corner, along the western slope, the southcentral region of the Bay of Campeche including Campeche Knolls, and last near the northwest corner of the Campeche Escarpment. In each region, the float data used were limited to those drifting between the $2200-$ and $3200-\mathrm{m}$ isobaths. One 6-day portion of one float track was removed in the southeastern group where the float was caught in bathymetry (see Fig. 6b) and exhibited westward motion not in character with the rest of the floats in this region. In this analysis, negative velocity corresponds to cyclonic flow along the boundary.

Along-isobath velocities were everywhere weaker than $\pm 10 \mathrm{~cm} \mathrm{~s}^{-1}$ except between late September 2013 and mid-January 2014 (Figs. 10b,c), that is, when Kraken was in the western Gulf. The velocities in all regions are weaker than $\pm 5 \mathrm{~cm} \mathrm{~s}^{-1}$ as Kraken enters the western Gulf (early August 2013) and exhibit strong fluctuations in speed or progressively increasing speed from October through December and then slow down in January when velocities everywhere along the boundary again return to weaker than $\pm 10 \mathrm{~cm} \mathrm{~s}^{-1}$. In the northwestern region, velocities show strong reversals in direction, in contrast with the general character of the other three regions. Speed variations in this region are up to $20 \mathrm{~cm} \mathrm{~s}^{-1}$, with approximately 1 month between peaks. These velocity reversals along the northwestern Gulf boundary may be due to TRWs: both Hamilton (1990) and Oey and Lee (2002) show a focusing of TRW energy in this region. In addition, Hamilton (1990) showed that the TRWs would precede the arrival of the LCE at the western boundary, and this may also be the case here: the strong velocity fluctuations observed in the float data precede the impact of the LCE on the western boundary.

South of $23^{\circ} \mathrm{N}$, the along-isobath velocity, generally cyclonic, increased from the southwest region to the southeast, and showed some indication of progressively peaking in time over about a 40-day period, from $\sim 1$ December to 10 January. Velocities in the southwest, where the bottom slope is less steep, were smaller in magnitude than in the other three regions, showing low speed oscillations of $\sim 5-10 \mathrm{~cm} \mathrm{~s}^{-1}$ and $\sim 20$ days between peaks. In the south-central region, floats measured weak $\left(-10 \mathrm{~cm} \mathrm{~s}^{-1}\right)$ cyclonic flow in October, weaker $\left(3 \mathrm{~cm} \mathrm{~s}^{-1}\right)$ anticyclonic flow in November, and then progressively strengthening cyclonic flow, up to $-20 \mathrm{~cm} \mathrm{~s}^{-1}$ by mid-December. The acceleration/deceleration events of the cyclonic flow measured by the floats in the eastern Bay of Campeche (Fig. 10b, green track, late December) were not gradual: for example, a float was traveling at speeds $<10 \mathrm{~cm} \mathrm{~s}^{-1}$, then accelerated to $20 \mathrm{~cm} \mathrm{~s}^{-1}$ over the course of 1-2 days, traveled at speeds over $20 \mathrm{~cm} \mathrm{~s}^{-1}$ for 8 days, then decelerated back to less than $10 \mathrm{~cm} \mathrm{~s}^{-1}$. In contrast, the floats at the corner of the Campeche Escarpment measured generally cyclonic flow for the entire period and 

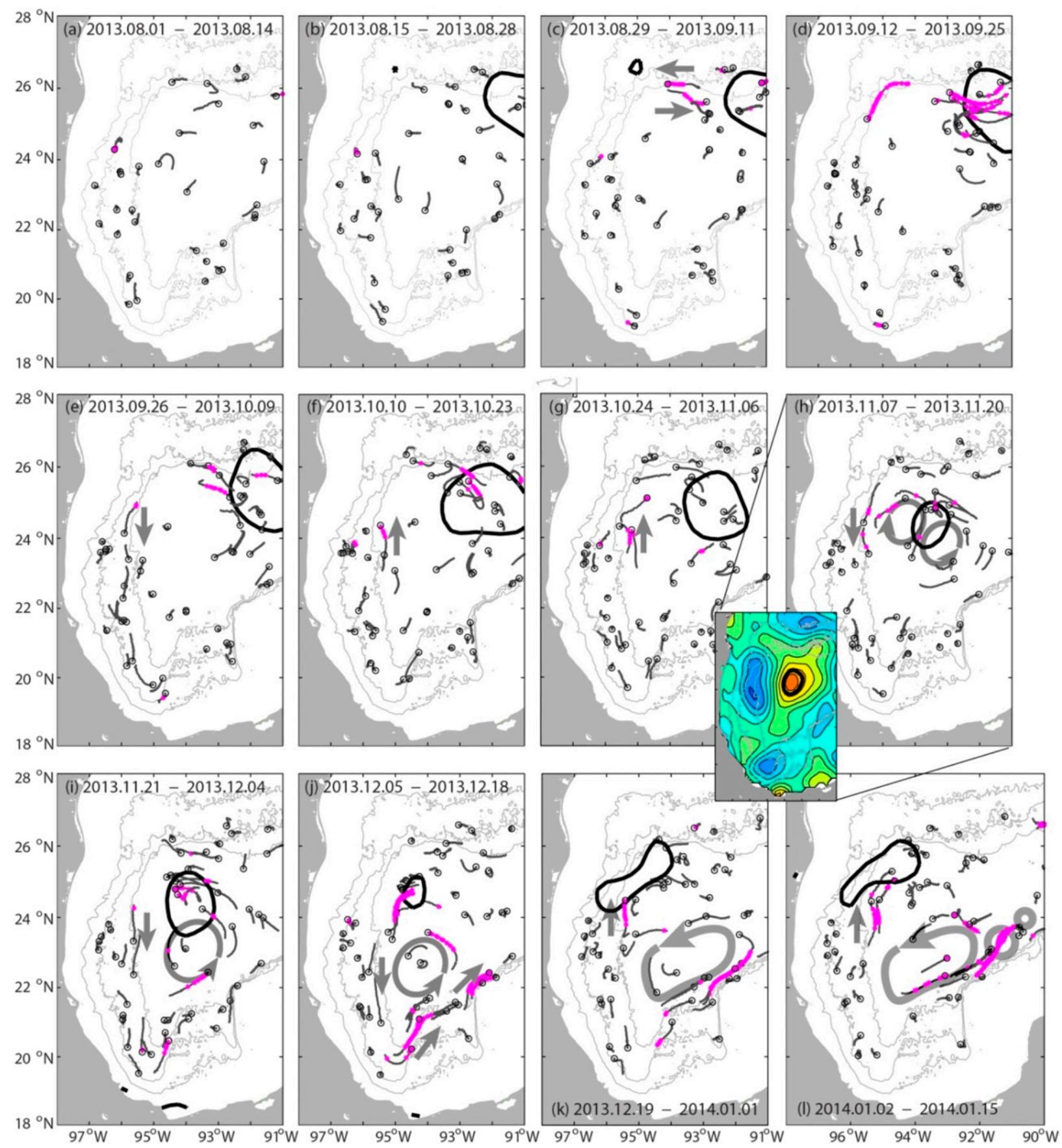

FIG. 9. (a)-(1) Time series of LCE Kraken and floats in western Gulf from 1 Aug 2013 through 15 Jan 2014, in 2-week segments. Float trajectory segments are marked with a circle indicating the last day of the two-week period. If the speed of the float is below $17 \mathrm{~cm} \mathrm{~s}^{-1}$ the trajectory is colored gray, if above $17 \mathrm{~cm} \mathrm{~s}^{-1}$ then is colored magenta. CCAR SSH $17-\mathrm{cm}$ contour is drawn as a black line, showing the progression of the LCE. The date chosen for the LCE is at the center of each 2-week time period, except for (j) where the LCE date is 6 days past the start date. Inset in (h) shows the fully contoured SSH field with a contour interval of $5 \mathrm{~cm}$ and the 17 -cm contour as a thick black line, for reference. The thick gray arrows and gray circles, indicating the newly formed CEEs, are schematic. Bathymetry contoured as in Fig. 1. 


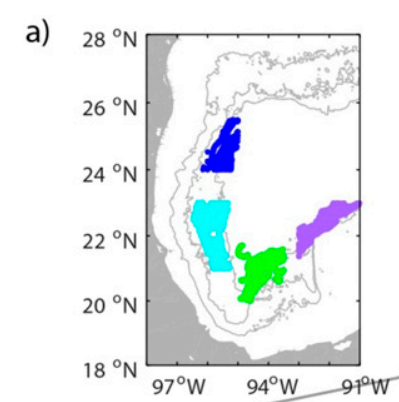

b)
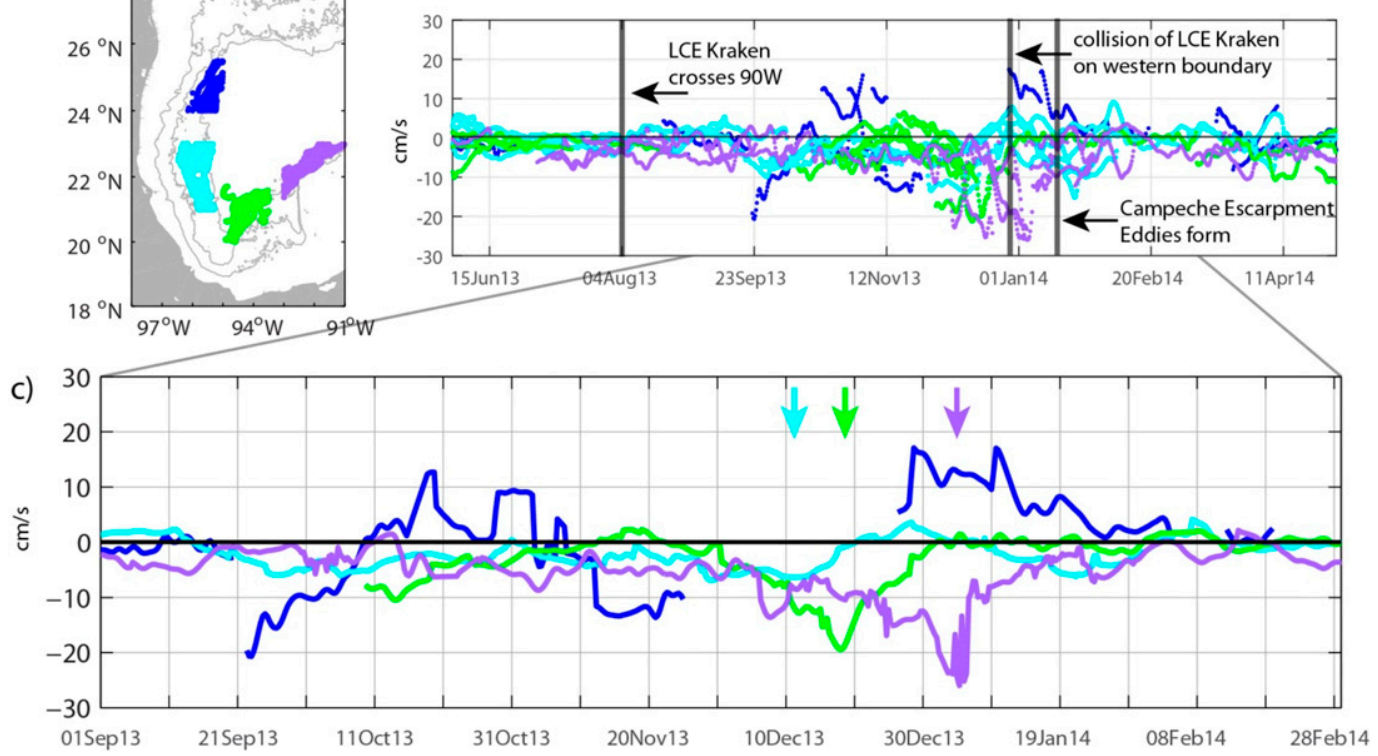

FIG. 10. Time series of along-isobath float velocity in four regions of the western Gulf. Negative (positive) velocity indicated cyclonic (anticyclonic) along-isobath flow. (a) Locations of trajectory data used in each of the four regions. (b) Time series of all the data used, color coded as in (a) to indicate which data are derived from which region. (c) Time series of mean velocity of all data of each region. Number of points per mean data point is inconsistent. Arrows, color coded as in (a), indicate time of greatest magnitude velocity for three regions.

exhibit the strongest mean speeds of all regions, up to $25 \mathrm{~cm} \mathrm{~s}^{-1}$. Peak velocities, measured by several floats in this location, occurred between 8 December and 6 January.

The disintegration of LCE Kraken, and the associated lower-layer dipole, appears to be correlated to an increase in cyclonic flow measured in the SAG and around the boundary of the western Gulf. In turn, the increase of velocity along the northwest Campeche Escarpment is circumstantially linked to the formation of CEEs.

\section{Discussion and summary}

\section{a. Comparing GOM eddies to other eddies}

We used wavelet analysis to identify coherent eddies in a new subsurface float dataset in the GOM. To our knowledge, these are the first ever observations of coherent eddies in the deep GOM, and the first census of such eddies in this basin. Such statistics on subsurface coherent eddies are extremely rare as they are only possible where large numbers of neutrally buoyant floats have been deployed. One study used the trajectories from $\sim 100$ isopycnal RAFOS floats released in the northern North Atlantic to identify long-lived cyclonic and anticyclonic subsurface eddies at the thermocline level (Shoosmith et al. 2005). The nearly equal distribution of cyclonic (23) and anticyclonic (26) eddies found in the GOM is similar to the $49 \%$ (51\%) cyclonic (anticyclonic) distribution (Shoosmith et al. 2005). At the sea surface, a global surface large-scale eddy survey derived from SSH data (Chelton et al. 2007) shows no preference for polarity. We believe that these are the only other large-scale surveys of coherent eddy distribution from observations. These two studies do show regional differences in polarity due to local dynamics, similar to what has been shown here for the GOM.

The percentage of these float data in a two-loop coherent eddy $(7 \%)$ was about half of that found by Shoosmith et al. (2005) in the northern North Atlantic $(15 \%)$. This may be due to data sampling or to the analytical method used here versus the subjective method used by Shoosmith et al. to identify eddies or may represent an actual regional difference. The mean duration of the deep Gulf eddies (50 days) was smaller than that of the North Atlantic eddies (84 days). This could reflect the fact that the GOM is a smaller, semienclosed basin where boundaries may be encountered sooner than in the North Atlantic, as well as the fact that the eddies are found in the deep layer, so bottom friction may also contribute. Such comparisons are perhaps only marginally interesting; since the Chelton et al. (2007) work focuses on surfaceintensified eddies, those in Shoosmith et al. (2005) are thermocline eddies that may be associated with surface-intensified eddies, while the eddies studied 
here occur at the deep, unstratified layer of the GOM, showing no surface signature.

Perhaps a more relevant comparison can be made between the CEEs and other known subsurface anticyclonic eddies observed with floats. These include cuddies (California Undercurrent eddies at $400 \mathrm{~m}$; Garfield et al. 1999), meddies (Mediterranean eddies, centered at 1000-m depth; Bower et al. 1997), and Tail of the Grand Banks (TGB) eddies (observed at 700$1500 \mathrm{~m}$; Elliott and Sanford 1986; Bower et al. 2013). In all cases, these eddies appear to form when a subsurface boundary current separates from the continental slope at a sharp corner in the isobaths, similar to the formation process of CEEs. CEEs are also similarly long-lived (on the scale of at least months) and energetic, with velocities in the range of $10-30 \mathrm{~cm} \mathrm{~s}^{-1}$.

Many of the floats that travel through the southeastern SAG have trajectories that exhibited some looping behavior downstream of the separation region (PPB) but did not end up trapped in coherent eddies. We found that the floats that end up in coherent vortices traveled through the eastern SAG when the SAG speed was fastest. Bower et al. (1997) seeded the Mediterranean Undercurrent with RAFOS floats just upstream of the meddy formation site near Cape St. Vincent, Portugal. Float speed in the undercurrent was up to $40 \mathrm{~cm} \mathrm{~s}^{-1}$, and in most cases (4/5), meddies formed when float velocity was greater than $20 \mathrm{~cm} \mathrm{~s}^{-1}$. Bower et al. (1997), invoking D'Asaro's (1988) formation mechanism (where torque induced by boundary friction provides the shear that winds up into anticyclonic eddies upon flow separation), proposed that eddy formation may be linked to boundary current velocity, with faster speeds generating more lateral shear between the jet maximum and the boundary. This may be a factor in CEE formation also.

Unlike the three other examples of subsurface anticyclonic eddies listed above, the vertical structure of the CEEs is completely unknown at this point: we checked through all historically available profile data in the HydroBase database, the Argo database, and APEX profiles collected as part of this project (Hamilton et al. 2018) and could find no vertical profiles coincident with the CEE observations. However, all deep current observations from moorings in the Gulf show either depth-independent flow below $800-1200 \mathrm{~m}$ or slightly near-bottom intensified (e.g., Hamilton 2009; Donohue et al. 2016; Tenreiro et al. 2018), consistent with weak stratification in the lower layer. Also, below $1000 \mathrm{~m}$, density barely varies with depth (Hamilton et al. 2018), so little geostrophic shear is expected in the lower layer. No surface expression was found in simultaneous sea surface height observations. We suspect that CEEs are most like the TGB eddies in vertical structure (Elliott and Sanford 1986): subthermocline, weakly stratified eddies occupying most of the lower layer.

The interior eddies, in the LC region, are briefly discussed in Hamilton et al. (2016b), and those investigated appear to be dynamically linked to the LC (Donohue et al. 2016). These, along with the small, energetic, dominantly anticyclonic boundary eddies (not shown in detail), both warrant further investigation.

\section{b. Evolution of the deep flow field in the western Gulf of Mexico}

Several numerical studies show that deep dipolar structures are generated underneath LCEs as they are formed in the eastern basin. As the upper-layer ring travels westward, the deep structures move with it, deforming as they are squeezed by the narrow passage at $\sim 88^{\circ} \mathrm{W}$, to then reform when the LCE reaches the western abyssal plain (Hurlburt and Thompson 1982; Sturges et al. 1993; Welsh and Inoue 2000; Romanou et al. 2004). The resulting deep southward flow under the center of the LCE deviates to the south the westward propagation of the upper-layer eddy over the abyssal plain (Cushman-Roisin et al. 1990; Sutyrin et al. 2003). It is unclear if these deep vortices are coherent eddies, or vorticity anomalies induced by Rossby waves (Sturges et al. 1993), which may explain why no floats were found looping around these structures, even though their trajectories do show flow consistent with a dipolar circulation under Kraken when it was present in the abyssal plain (Figs. 9h and S1).

The modeling studies show that, as the LCE approaches the western boundary, the anticyclonic component of the deep modon dissipates, while the cyclonic part remains in the western abyssal plain where it first strengthens and then slowly dissipates (Sturges et al. 1993; Welsh and Inoue 2000; Romanou et al. 2004). The LCE tends to move northward along the slope because of the image effect, and TRWs are generated in the bottom layer owing to the interaction with the boundary (Sutyrin et al. 2003). Southward boundary currents are produced along the western boundary that are not permanent but can be strong (Romanou et al. 2004). The study by Tenreiro et al. (2018) is the first to show observational evidence of relative vorticity distributions consistent with modons under LCEs in the western GOM. They also observe enhanced cyclonic vorticity over the abyssal plain, as well as southward boundary flows as the LCE impacts the western slope, which they attribute to both the flow of the trailing deep cyclone as well as to flow rectification induced by the TRWs (i.e., the balance between bottom friction and the divergence of the vertically integrated Reynolds stresses; e.g., Mizuta and Hogg 2004). Hence, the presence of the LCE 

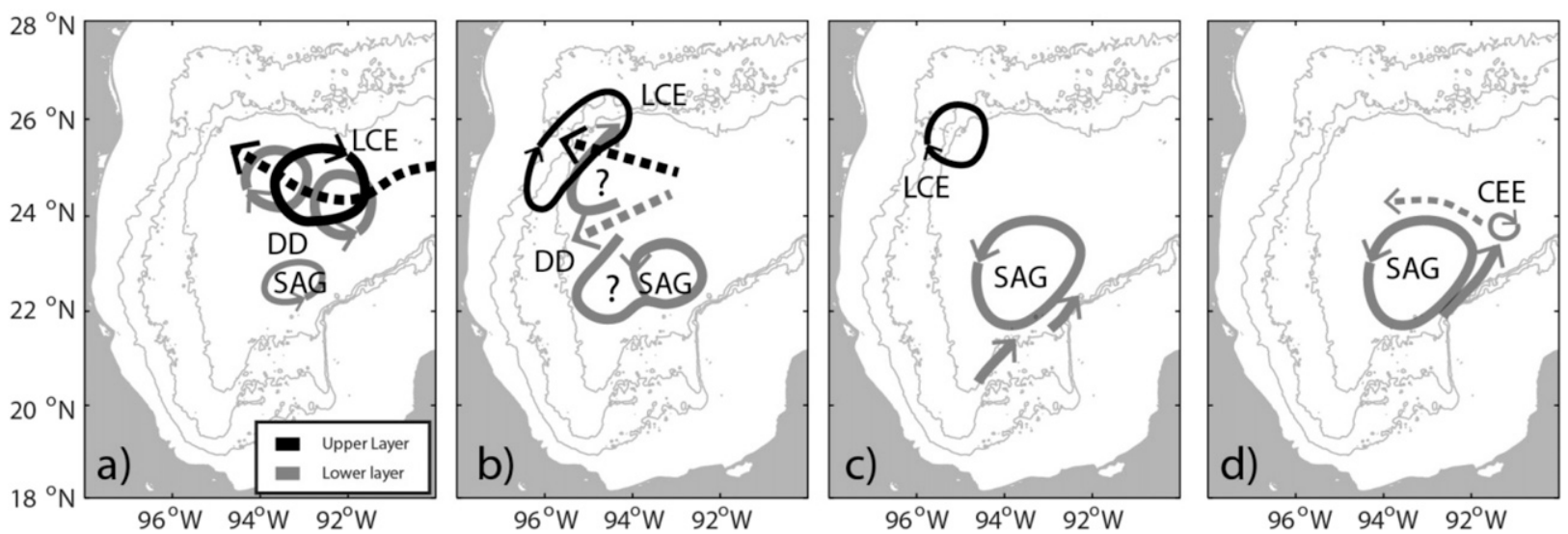

FIG. 11. Schematic series that depicts a possible sequence of events for the western Gulf. (a) TRWs along the slope boundary and the LCE and dipole traveling together. (b) The displacement of the LCE from the lower-layer dipole circulation and dissipation at the western boundary through undetermined mechanisms. (c) Diminishing LCE in the upper layer as SAG strengthens and speed increases in the Bay of Campeche, across the Campeche Knolls. (d) SAG remains energized, speed increase at the northwest Campeche Escarpment, and CEE formation. The dashed lines indicate approximate direction of travel of the LCE, DD, and CEE.

in the abyssal plain as well as its interaction with the western boundary seems to lead to intensification and decay of the lower-layer flows.

In this study, only one LCE was addressed. Kraken followed more of a northern route into the western basin, traveling at first near the northern boundary (Figs. 9a-f), then moving southwestward onto the abyssal plain (Figs. 9g-i), and finally impacting the northwest corner where it ultimately dissipated (Figs. 9j-1). The float data show low velocities in the western basin before the arrival of Kraken, and higher velocities once the LCE reaches $90^{\circ} \mathrm{W}$. The flow strengthening is first observed along the northern boundary (Figs. 9c-e), when Kraken is interacting with the slope, and afterward in the abyssal plain and along the western and southern boundaries (Figs. 9g-1). In addition, the trajectories show flow consistent with a dipolar structure when the ring was over the abyssal plain (Fig. 9h) followed by stronger cyclonic circulation both in the abyssal plain as well as along the Bay of Campeche slope. All these results are consistent with the modeling studies as well as the mooring observations mentioned earlier.

One can argue that the dipolar structure is only briefly clearly observed by the float trajectories. The idealized experiments by Sutyrin et al. (2003) show that LCEs that travel along the northern slope do not develop a deep dipolar structure, but rather just induce TRWs. This may explain why the dipolar structure is only discernible by the float trajectories once the LCE separates from the northern boundary and moves into the abyssal plain. Soon after, the ring encounters the northwest boundary and the deep anticyclonic circulation is confined to that corner, deformed and not as clearly discerned by the floats, while the cyclonic component is clearly shown by the trajectories until the end of the observational period.

In summary, the float observations are consistent with a dipole coupled to an upper-layer LCE. As the anticyclone disintegrates in the northwest boundary, the cyclonic eddy strengthens over the abyssal plain, enhancing the intensity of the SAG flow. In addition, stronger cyclonic flow is observed along the southern boundary: the mechanism by which this happens is unclear, although it may be related to rectification of the TRWs generated when the LCE impacts the boundary (Tenreiro et al. 2018). Both the strengthening of the SAG and the boundary flow result in the peak in speed measured by the floats at the northwest corner of the Campeche Escarpment (Fig. 7b) that precedes the formation of the CEEs.

A cartoon summarizing the formation sequence for CEEs is drawn in Fig. 11. The panels show a deep dipole linked with an upper layer LCE drifting westward (Fig. 11a). The LCE and dipole separate, and the dipole breaks up as it impinges on the western boundary (Fig. 11b). Subsequently, there is a cyclonic propagation of energy in the boundary current and an increase in speed of the SAG (Figs. 11c,d). Finally, the acceleration at the Campeche Escarpment corner forces coherent eddy formation (Fig. 11d). Once these events are complete the regional circulation slows, similar to the conditions present before the arrival the LCE and the deep dipole. This should be considered a hypothesis to be tested, based on the synthesis of the best spatially distributed velocity dataset in the western Gulf collected to date, recognizing that there are still gaps in a complete understanding of the response of the deep layer to LCEs 
entering the western Gulf and the possible link to CEE formation.

These Lagrangian data have yielded the first largescale description of the deep circulation in the western Gulf of Mexico, including a basinwide census of deep coherent eddies and, along with the mean circulation and statistics provided by PPB, advance our understanding of temporal variability in the lower layer. Another deep circulation program centered in the western Gulf as part of the Gulf of Mexico Research Consortium (CIGoM) will be completed in 2019, providing many more deep RAFOS trajectories and the possibility to confirm with in situ observations the persistence of the CEE formation mechanism present in the float dataset analyzed here. Regional models do show the separation of the boundary current at the Campeche Escarpment as well as anticyclonic vorticity in the region where we observed the CEEs (J. Sheinbaum 2018, personal communication), so a model study dedicated to the role played by LCEs on the deep flows over the abyssal plain and along the slopes of the Bay of Campeche and Campeche Escarpment, would certainly help address the hypothesis presented here on how the CEEs are formed.

Acknowledgments. The authors were supported by the Department of the Interior, Bureau of Ocean Energy Management (BOEM), Contract M10PC00112 to Leidos, Inc., Raleigh, North Carolina. The authors also wish to acknowledge the enthusiastic support of Dr. Alexis Lugo-Fernández, the BOEM Contracting Officer's Technical Representative, during the study. Further support for this work was provided through the National Academies of Science Gulf Research Program Grant 2000006422 SA-1, entitled "Synthesis of Historical Observations using Novel Model Approaches to Improve Understanding and Predictability of Deep Gulf of Mexico Circulation" through a sub-award from Florida State University. Thanks go to the captains and crews of the R/V Pelican and B/O Justo Sierra, J. Malbrough (LUMCON), J. Singer (Leidos), J. Valdes (WHOI), B. Guest (WHOI), and the CANEK group (CICESE). The authors thank the two anonymous reviewers who provided thoughtful and thorough comments.

\section{REFERENCES}

Athié, G., J. Candela, J. Ochoa, and J. Sheinbaum, 2012: Impact of Caribbean cyclones on the detachment of Loop Current anticyclones. J. Geophys. Res., 117, C03018, https://doi.org/ 10.1029/2011JC007090.

Bower, A., L. Armi, and I. Ambar, 1997: Lagrangian observations of meddy formation during a Mediterranean undercurrent seeding experiment. J. Phys. Oceanogr., 27, 2545-2575, https://doi.org/ 10.1175/1520-0485(1997)027<2545:LOOMFD>2.0.CO;2.
— R. Hendry, D. Amrhein, and J. Lilly, 2013: Direct observation of formation and propagation of subpolar eddies into the subtropical North Atlantic. Deep-Sea Res. II, 85, 15-41, https://doi.org/10.1016/j.dsr2.2012.07.029.

Candela, J., J. Sheinbaum, J. Ochoa, A. Badan, and R. Leben, 2002: The potential vorticity flux through the Yucatan Channel and the Loop Current in the Gulf of Mexico. Geophys. Res. Lett., 29, 2059, https://doi.org/10.1029/2002GL015587.

Chelton, D. B., M. G. Schlax, R. M. Samelson, and R. A. de Szoeke, 2007: Global observations of large oceanic eddies. Geophys. Res. Lett., 34, L15606, https://doi.org/10.1029/2007GL030812.

Curry, R., and C. Nobre, 2013: Hydrobase3 technical report. Woods Hole Oceanographic Institution Tech. Rep., 38 pp.

Cushman-Roisin, B., B. Tang, and E. P. Chassignet, 1990: Westward motion of mesoscale eddies. J. Phys. Oceanogr., 20, 758-768, https:// doi.org/10.1175/1520-0485(1990)020<0758:WMOME >2.0.CO;2.

D’Asaro, E. A., 1988: Generation of submesoscale vortices: A new mechanism. J. Geophys. Res., 93, 6685-6693, https://doi.org/ 10.1029/JC093iC06p06685.

Davis, R. E., J. T. Sherman, and J. Dufour, 2001: Profiling ALACEs and other advances in autonomous subsurface floats. J. Atmos. Oceanic Technol., 18, 982-993, https://doi.org/ 10.1175/1520-0426(2001)018<0982:PAAOAI >2.0.CO;2.

Donohue, K. A., P. Hamilton, K. Leaman, R. Leben, M. Prater, D. R. Watts, and E. Waddell, 2007: Exploratory study of deepwater currents in the Gulf of Mexico. U.S. Dept. of the Interior Tech. Rep. MMS 2006-074, 408 pp., https://www. boem.gov/ESPIS/4/4222.pdf.

,,-- R. Leben, R. Watts, and E. Waddell, 2008: Survey of deepwater currents in the northwestern Gulf of Mexico. U.S. Dept. of the Interior Tech. Rep., 364 pp.

— D. R. Watts, P. Hamilton, R. Leben, and M. Kennelly, 2016: Loop Current eddy formation and baroclinic instability. Dyn. Atmos. Oceans, 76, 195-216, https://doi.org/10.1016/ j.dynatmoce.2016.01.004.

Elliott, B. A., and T. B. Sanford, 1986: The subthermocline lens D1. Part I: Description of water properties and velocity profiles. J. Phys. Oceanogr., 16, 532-548, https://doi.org/ 10.1175/1520-0485(1986)016<0532:TSLDPI>2.0.CO;2.

Fratantoni, P. S., T. N. Lee, G. P. Podesta, and F. Muller-Karger, 1998: The influence of Loop Current perturbations on the formation and evolution of Tortugas eddies in the southern Straits of Florida. J. Geophys. Res., 103, 24 759-24 779, https:// doi.org/10.1029/98JC02147.

Garfield, N., C. A. Collins, R. G. Paquette, and E. Carter, 1999: Lagrangian exploration of the California Undercurrent, 199295. J. Phys. Oceanogr., 29, 560-583, https://doi.org/10.1175/ 1520-0485(1999)029<0560:LEOTCU>2.0.CO;2.

Hamilton, P., 1990: Deep currents in the Gulf of Mexico. J. Phys. Oceanogr., 20, 1087-1104, https://doi.org/10.1175/1520-0485(1990) 020<1087:DCITGO > 2.0.CO;2.

- 2009: Topographic Rossby waves in the Gulf of Mexico. Prog. Oceanogr., 82, 1-31, https://doi.org/10.1016/j.pocean.2009.04.019.

—, K. Donohue, C. Hall, R. R. Leben, H. Quian, J. Sheinbaum, and D. R. Watts, 2014: Observations and dynamics of the Loop Current. U.S. Dept. of the Interior Tech. Rep. BOEM 2015-006, 417 pp., https://www.boem.gov/ESPIS/5/5471.pdf.

—_, A. Lugo-Fernández, and J. Sheinbaum, 2016a: A Loop Current experiment: Field and remote measurements. Dyn. Atmos. Oceans, 76, 156-173, https://doi.org/10.1016/ j.dynatmoce.2016.01.005.

_ A. Bower, H. Furey, R. R. Leben, and P. Peìrez-Brunius, 2016b: Deep circulation in the Gulf of Mexico: A Lagrangian 
study. U.S. Dept. of the Interior Tech. Rep. BOEM 2016-081, 289 pp., https://www.boem.gov/ESPIS/5/5583.pdf.

—_, R. Leben, A. Bower, H. Furey, and P. Pérez-Brunius, 2018: Hydrography of the Gulf of Mexico using autonomous floats. J. Phys. Oceanogr., 48, 773-794, https://doi.org/ 10.1175/JPO-D-17-0205.1.

Hurlburt, H., and J. Thompson, 1982: The dynamics of the Loop Current and shed eddies in a numerical model of the Gulf of Mexico. Hydrodynamics of Semi-Enclosed Seas, J. Nihoul, Ed., Elsevier, 243-298.

Jouanno, J., J. Ochoa, E. Pallàs-Sanz, J. Sheinbaum, F. AndradeCanto, J. Candela, and J.-M. Molines, 2016: Loop Current frontal eddies: Formation along the Campeche Bank and impact of coastally trapped waves. J. Phys. Oceanogr., 46, 33393363, https://doi.org/10.1175/JPO-D-16-0052.1.

Kolodziejczyk, N., J. Ochoa, J. Candela, and J. Sheinbaum, 2011: Deep currents in the Bay of Campeche. J. Phys. Oceanogr., 41 1902-1920, https://doi.org/10.1175/2011JPO4526.1.

Leben, R. R., 2005: Altimeter-derived Loop Current metrics. Circulation in the Gulf of Mexico: Observations and Models, W. Sturges and A. Lugo-Fernandez, Eds., Amer. Geophys. Union, 181-201.

— , G. H. Born, and B. R. Engebreth, 2002: Operational altimeter data processing for mesoscale monitoring. Mar. Geod., 25, 3-18, https://doi.org/10.1080/014904102753516697.

Lilly, J. M., and J.-C. Gascard, 2006: Wavelet ridge diagnosis of time-varying elliptical signals with application to an oceanic eddy. Nonlinear Processes Geophys., 13, 467-483, https:// doi.org/10.5194/npg-13-467-2006.

_ , and S. C. Olhede, 2009a: Higher-order properties of analytic wavelets. IEEE Trans. Signal Process., 57, 146-160, https:// doi.org/10.1109/TSP.2008.2007607.

— and - 2009b: Wavelet ridge estimation of jointly modulated multivariate oscillations. Proc. 43rd Asilomar Conf. on Signals, Systems, and Computers, Pacific Grove, CA, IEEE, 452-456.

— bandwidth. IEEE Trans. Signal Process., 58, 591-603, https:// doi.org/10.1109/TSP.2009.2031729.

- , and $-2010 \mathrm{~b}$ : On the analytic wavelet transform. IEEE Trans. Inf. Theory, 56, 4135-4156, https://doi.org/10.1109/ TIT.2010.2050935.

- - and - 2012: Analysis of modulated multivariate oscillations. IEEE Trans. Signal Process., 60, 600-612, https:// doi.org/10.1109/TSP.2011.2173681.

Mizuta, G., and N. G. Hogg, 2004: Structure of the circulation induced by a shoaling topographic wave. J. Phys. Oceanogr., 34 1793-1810, https://doi.org/10.1175/1520-0485(2004)034<1793: SOTCIB $>2.0 . \mathrm{CO} ; 2$.

Oey, L., and H.-C. Lee, 2002: Deep eddy energy and topographic Rossby waves in the Gulf of Mexico. J. Phys. Oceanogr., 32, 3499-3527, https://doi.org/10.1175/1520-0485(2002)032<3499: DEEATR $>2.0 . \mathrm{CO} ; 2$

— circulation in the Gulf of Mexico: A review of numerical models and future challenges. Circulation in the Gulf of Mexico: Observations and Models, Geophys. Monogr., Vol. 161, Amer. Geophys. Union, 31-56.

Pérez-Brunius, P., P. García-Carrillo, J. Dubranna, J. Sheinbaum, and J. Candela, 2013: Direct observations of the upper layer circulation in the southern Gulf of Mexico. Deep-Sea Res. II, 85, 182-194, https://doi.org/10.1016/j.dsr2.2012.07.020.

- H. Furey, A. Bower, P. Hamilton, J. Candela, P. GarcíaCarrillo, and R. Leben, 2018: Dominant circulation patterns of the deep Gulf of Mexico. J. Phys. Oceanogr., 48, 511-529, https://doi.org/10.1175/JPO-D-17-0140.1.

Romanou, A., E. P. Chassignet, and W. Sturges, 2004: Gulf of Mexico circulation within a high-resolution numerical simulation of the North Atlantic Ocean. J. Geophys. Res., 109, C01003, https://doi.org/10.1029/2003JC001770.

Rossby, T., D. Dorson, and J. Fontaine, 1986: The RAFOS system. J. Atmos. Oceanic Technol., 3, 672-679, https://doi.org/ 10.1175/1520-0426(1986)003<0672:TRS >2.0.CO;2.

Schmitz, W. J., 2005: Cyclones and westward propagation in the shedding of anticyclonic rings from the Loop Current. Circulation in the Gulf of Mexico: Observations and Models, Geophys. Monogr., Vol. 161, Amer. Geophys. Union, 241-261.

Sheinbaum, J., A. Badan, J. Ochoa, J. Candela, D. Rivas, and J. I. González, 2007: Full-water column current observations in the central Gulf of Mexico: Final report. U.S. Dept. of the Interior Tech. Rep. MMS 2007-022, 68 pp., https://www.boem.gov/ ESPIS/4/4258.pdf.

, G. Athié, J. Candela, J. Ochoa, and A. Romero-Arteaga, 2016: Structure and variability of the Yucatan and Loop Currents along the slope and shelf break of the Yucatan Channel and Campeche Bank. Dyn. Atmos. Oceans, 76, 217 239, https://doi.org/10.1016/j.dynatmoce.2016.08.001.

Shoosmith, D. R., P. L. Richardson, A. S. Bower, and H. T. Rossby, 2005: Discrete eddies in the northern North Atlantic as observed by looping RAFOS floats. Deep-Sea Res. II, 52, $627-$ 650, https://doi.org/10.1016/j.dsr2.2004.12.011.

Sturges, W., and R. Leben, 2000: Frequency of ring separations from the Loop Current in the Gulf of Mexico: A revised estimate. J. Phys. Oceanogr., 30, 1814-1819, https://doi.org/ 10.1175/1520-0485(2000)030<1814:FORSFT>2.0.CO;2.

_ J. C. Evans, and S. Welsh, 1993: Separation of warm-core rings in the Gulf of Mexico. J. Phys. Oceanogr., 23, 250-268, https:// doi.org/10.1175/1520-0485(1993)023<0250:SOWCRI >2.0.CO;2.

_ N. G. Hoffmann, and R. R. Leben, 2010: A trigger mechanism for Loop Current ring separations. J. Phys. Oceanogr., 40, 900-913, https://doi.org/10.1175/2009JPO4245.1.

Sutyrin, G. G., G. D. Rowe, L. M. Rothstein, and I. Ginis, 2003: Baroclinic eddy interactions with continental slopes and shelves. J. Phys. Oceanogr., 33, 283-291, https://doi.org/ 10.1175/1520-0485(2003)033<0283:BEIWCS > 2.0.CO;2.

Tenreiro, M., J. Candela, E. P. Sanz, J. Sheinbaum, and J. Ochoa, 2018: Near-surface and deep circulation coupling in the western Gulf of Mexico. J. Phys. Oceanogr., 48, 145-161, https://doi.org/10.1175/JPO-D-17-0018.1.

Vidal, V. M. V., F. V. Vidal, and J. M. Pérez-Molero, 1992: Collision of a Loop Current anticyclonic ring against the continental shelf slope of the western Gulf of Mexico. J. Geophys. Res., 97, 2155-2172, https://doi.org/10.1029/91JC00486.

Vukovich, F. M., 2007: Climatology of ocean features in the Gulf of Mexico using satellite remote sensing data. J. Phys. Oceanogr., 37, 689-707, https://doi.org/10.1175/JPO2989.1.

Welsh, S. E., and M. Inoue, 2000: Loop Current rings and the deep circulation in the Gulf of Mexico. J. Geophys. Res., 105, 16 951-16 959, https://doi.org/10.1029/2000JC900054.

Wooding, C., H. Furey, and M. Pacheco, 2005. RAFOS float processing at the Woods Hole Oceanographic Institution. Woods Hole Oceanographic Institution Tech. Rep. WHOI-05-02, $35 \mathrm{pp}$.

Zavala-Hidalgo, J., S. Morey, and J. O'Brien, 2003: Cyclonic eddies northeast of the Campeche Bank from altimetry data. J. Phys. Oceanogr., 33, 623-629, https://doi.org/10.1175/1520-0485 (2003)033<0623:CENOTC $>2.0 . \mathrm{CO} ; 2$ 